\title{
A Identidade Profissional em análise: um estudo de revisão sistemática da literatura
}

Professional identity in analysis: a sistematic review of the literature

\author{
Luciano Vozniak* \\ Faculdade de Desporto da Universidade do Porto \\ Isabel Mesquita** \\ Faculdade de Desporto da Universidade do Porto \\ Paula Fazendeiro Batista*** \\ Faculdade de Desporto da Universidade do Porto
}

Resumo Este é estudo de revisão sistemática da literatura, cujo objetivo foi cartografar a investigação em língua portuguesa de 2003 a 2013, no campo da identidade e identidade profissional. A pesquisa foi efetuada em revistas categorizadas na Qualis na área da educação, num total de 30 revistas, utilizando os termos "Identidade" e "Identidade Profissional". Os resultados evidenciaram que os estudos tiveram um incremento, principalmente a partir do ano de 2007 e no âmbito da docência, recorrendo predominantemente a metodologias qualitativas. A identidade surge como um construto de natureza dinâmica, que se transforma em resultado das experiências pesssoais, formativas e profissionais.

PALAVRAS-CHAVE: Revisão sistemática da literatura; Identidade; Identidade profissional.

Abstract This study is a systematic review of the literature. The aim is to map the research in Portuguese language from 2003 to 2013, in the field of identity and professional identity. The research was conducted in journals categorized in Qualis in the education field of a total of 30 journals, using the terms "identity" and "Professional Identity". The results showed that the studies had an increase, especially after 2007 and in the context of teaching, using predominantly qualitative methodologies. The identity emerges as a construct with dynamic nature which mostly result of personal, educational and professional experiences.

KEYWORDS: Systematic review of the literature; Identity; Professional identity. 


\section{Introdução}

A Identidade Profissional (IP) e as questões que rodeiam o construto, nomeadamente o conceito de identidade, têm tido, ao longo do tempo, um lugar de destaque na literatura (e.g, DUBBAR, 1995; GIDDENS, 1994; LOPES, 2004). De facto, face à transversalidade da problemática da identidade em todas as culturas e aos diversos grupos, designadamente os de natureza profissional, aceita-se que esta seja objeto de estudo sistemático. Acrescem as transformações sociais que ocorrem nos distintos campos de trabalho, tornando premente a necessidade de transformação e reconfiguração da identidade associada ao local de trabalho, ou seja da(s) identidade(s) profissional(ais). Neste contexto, é necessário que a pesquisa das questões inerentes à IP acompanhe este quadro de alterações.

Relativamente ao conceito de identidade, coexistem várias perspetivas, embora todas assumam que este é um conceito múltiplo, não se reportando a um atributo fixo. Com efeito, a identidade é considerada um elemento de natureza dinâmica, relacional e situacional (AKKERMAN; MEIJER, 2011; BEAUCHAMP; THOMAS, 2009; BEIJAARD; MEIJER; VERLOOP, 2004), que implica a criação de sentido e (re)interpretação dos próprios valores e experiências (GIDDENS, 1994). A identidade não é assim um dado imutável, nem externo, que possa ser adquirido, mas é um processo de construção do sujeito historicamente situado (PIMENTA, 2005). Já Dubar (1997) materializa o processo situado como sendo o resultado da socialização, que compreende o cruzamento dos processos relacionais e biográficos ${ }^{1}$. Paralelamente, Owens et al. (2010) e Stets e Burke (2000) atribuem ao conceito duas dimensões: a individual e a coletiva. A dimensão individual reporta-se ao processo de internalização das posições sociais e dos seus significados - vertente pessoal - e a dimensão coletiva ao impacto dos significados culturais e das situações sociais na identificação de um indivíduo com um grupo - vertente social (DUBAR, 1997; GIDDENS, 1997).

Outro elemento que emerge é que todas as pessoas possuem múltiplas identidades inter-relacionadas entre si (AKKERMAN; MEIJER, 2011), um 'core identity' (GEE, 2001), que lhes confere uma certa unicidade. Face a este quadro, compreende-se que a construção da identidade é um processo contínuo de socialização, onde a forma como o indivíduo se percebe no futuro, está intimamente relacionado com a forma como este é visto nas interações do seu quotidiano, seja no contexto pessoal, seja no laboral.

Assim, a IP é uma das muitas identidades sociais do indivíduo, sendo aquela que é ancorada nas representações, práticas e saberes profissionais e que depende do contexto de exercício profissional do indivíduo (PIMENTA, 2005). Neste enquadramento, o contexto laboral é um local e um momento propício para o indivíduo interagir socialmente, sendo essa interação necessária à aquisição da IP. Por exemplo, no âmbito laboral docente, os professores utilizam o espaço de trabalho para fazerem adaptações de natureza individual e coletiva, permitindo-lhes adquirir e transformar a sua IP docente (FACCI, 2004). Neste entendimento, sustenta-se a ideia de que a IP docente resulta de uma relação entre as experiências pessoais, o contexto social e institucional (NÓVOA, 2000). 
Face ao exposto, e entendendo que a sistematização da investigação da temática da identidade profissional no âmbito da língua portuguesa é um terreno por explorar, o presente estudo pretendeu cartografar a investigação existente em língua portuguesa na última década (2003 a 2013) no campo da Identidade e IP, na procura de renovados contributos para o entendimento do modo como a IP se (re)constrói e (re)configura.

\section{Metodologia}

$\mathrm{Na}$ presente pesquisa utilizaram-se os pressupostos de uma revisão sistemática da literatura. Para Petticrew e Roberts (2006) e Savin-Baden e Major (2010), a revisão sistemática é um meio rigoroso de sintetizar e incrementar o conhecimento da literatura relevante, clarificando temas, indicando tópicos para pesquisas futuras e priorizando as temáticas que carecem de maior investimento.

O primeiro passo efetuado desta revisão foi selecionar as revistas. Deste modo, atendendo ao propósito desta revisão, definiu-se como primeiro critério de inclusão a listagem das revistas da Qualis ${ }^{2}$, tendo sido selecionadas as revistas com publicações na área da educação, num total de 30 revistas. De seguida procedeu-se à pesquisa em cada revista, na última década (2003 a 2013), utilizando os termos «Identidade» e «Identidade Profissional», nos campos título e resumo, cujos resultados foram objeto de filtragem pelos critérios de inclusão e de exclusão (Tabela 1).

Tabela 1 - Fluxograma do processo de pesquisa bibliográfica

"Termos da pesquisa

Fontes de pesquisa

Revistas Qualis num total de 30

Total artigos 118

Remoção de duplicados

Removidos 5

Total 113

Seleção por critérios de inclusão e exclusão

(excluídos os trabalhos que não tratavam de forma específica a temática em foco, os capítulos de livro, as dissertações e os que não estavam escritos na língua portuguesa)

Eliminados 78

Total 35 (16 estudos de natureza teórica e 19 empíricos)

Em termos organizacionais, optou-se por analisar inicialmente os estudos de natureza teórica e depois os empíricos. Os estudos foram mapeados em quadros, recorrendo aos descritores utilizados por Cardoso, Batista e Graça (2014): a) título; b) autor, ano e local de realização do estudo; b) propósito do estudo; c) conceito de Iden- 
tidade Profissional; d) metodologia - participantes, instrumentos e procedimentos de análise; e f) principais resultados (ver exemplo de sistematização na Tabela 2).

Tabela 2 - sistematização de um estudo teórico em função dos descritores enunciados por Cardoso, Batista e Graça (2014)

Santos (2004). Emergência da cultura do efémero no contexto sócio laboral e identidade profissional: Dos não-lugares aos não-locais de trabalho. Portugal

\begin{tabular}{|c|c|c|}
\hline Propósito do estudo & Metodologia & Resultados e conclusões \\
\hline $\begin{array}{l}\text { Analisar as transformações } \\
\text { do trabalho e da IP } \\
\text { decorrentes da atual } \\
\text { sociedade da informação. }\end{array}$ & $\begin{array}{l}\text { Qualitativa } \\
\text { Procedimentos: } \\
\text { Parte dos estudos de } \\
\text { AUGÉ (1994), FISHER } \\
(1994), \text { SANTOS e } \\
\text { COELHO (1999) para } \\
\text { analisar as transformações } \\
\text { do trabalho e daidentidade } \\
\text { profissional decorrentes } \\
\text { da atual Sociedade da } \\
\text { Informação. }\end{array}$ & $\begin{array}{l}\text { A construção e aquisição de uma } \\
\text { IP relaciona-se com os processos } \\
\text { de construção e os modos de } \\
\text { expressão da Identidade do } \\
\text { Homem. } \\
\text { Alterações da configuração laboral } \\
\text { em resultado da sociedade da } \\
\text { informação: o trabalho separa-se } \\
\text { progressivamente do emprego- } \\
\text { local-lugar, para ser concretizado } \\
\text { em contextos caracterizados } \\
\text { como não-lugares ou não-locais } \\
\text { de trabalho. }\end{array}$ \\
\hline
\end{tabular}

Conceito de IP: É uma das facetas axiais da identidade social, esta constrói-se e reconstrói-se no jogo das interações sócio laborais.

$\mathrm{Na}$ apresentação e discussão dos resultados, recorreu-se à síntese narrativa, um dos métodos mais utilizados nas revisões sistemáticas da literatura (DENYER; TRANFIELD, 2006), que englobam os seguintes passos: a) organizar a descrição dos estudos em categorias lógicas; b) analisar os resultados dentro de cada categoria; c) sintetizar os resultados transversais aos estudos. Refira-se ainda que para dar cumprimento à síntese dos resultados foi utilizado em primeira instância, em ambas as componentes - estudos teóricos e empíricos -, um processo dedutivo, tendo resultado na definição de duas categorias: 1) cronologia e local de realização dos estudos e 2) propósitos dos estudos. Numa segunda fase o processo foi indutivo. Assim, os temas definidos para os estudos de natureza teórica foram: 1) construção da IP e relações com o trabalho; 2) construção da IP do professor; e para os estudos empíricos: 1) construção da identidade docente: percursos identitários e desenvolvimento continuado e 2) IP docente e o contexto [lugar e espaço] de intervenção.

\section{Resultados e discussão}

\section{Artigos de natureza teórica}

Existe uma elevada dispersão das publicações, embora a centração seja em revistas brasileiras (13). De facto, os 16 estudos distribuem-se por 15 revistas, sendo que apenas a Revista Educação publicou 2 artigos (Tabela 3). 
Tabela 3 - Listagem de revistas e número de estudos teóricos publicados

\begin{tabular}{l|c}
\hline Revistas & No de artigos teóricos \\
\hline Civitas - Revista de Ciências Sociais & 1 \\
\hline Revista Diálogo Educacional & 1 \\
\hline Revista Sociedade e Cultura & 1 \\
\hline Revista Teias & 1 \\
\hline Revista antropológicas & 1 \\
\hline Revista Brasileira De Ciências Sociais & 1 \\
\hline Revista Brasileira de Educação Física e Esporte & 1 \\
\hline Revista ECCOS & 2 \\
\hline Revista Educação & 1 \\
\hline Revista Educação \& Linguagem & 1 \\
\hline Revista Educação e Pesquisa & 1 \\
\hline Revista Educação em Perspectiva & 1 \\
\hline Revista Quaestio & 1 \\
\hline Revista Saúde e Sociedade & 1 \\
\hline Sísifo - Revista de Ciências da Educação & 1 \\
\hline
\end{tabular}

Grande parte dos artigos de natureza concetual são de 2011, num total de 4 publicações. Nos anos de 2003 e 2005, foram publicados 3 artigos, por ano, e entre 2006 e 2010 apenas 3 artigos, verificando-se o mesmo entre 2012 e 2013. Relativamente ao local de publicação, 2 foram publicados em Portugal e 14 no Brasil.

$\mathrm{Na}$ metodología, prevalece a qualitativa, materializando-se na exploração dos processos de construção da identidade e IP (15) e numa revisão sistemática da literatura (GOMES; et al., 2013). Refira-se que alguns autores recorreram, de forma adicional, a dados de estudos empíricos de forma a explicitarem os conceitos em análise (e.g. TAVARES, 2008; WINKLER, 2011). Outra evidência é que os estudos se repartem entre os processos de construção identitária sem especificação da área profissional (e.g. SANTOS, 2004; WINKLER, 2011; SILVA, 2011) e a IP na área da docência (e.g. FRANGELLA, 2003; FERREIRA, 2011; GARCIA; HYPOLITO; VIEIRA, 2005), sendo que apenas dois estudos focam a área da saúde (CARVALHO, 2012; TAVARES, 2008).

Com base nos propósitos de estudo e atendendo aos principais resultados emergiram duas grandes temáticas: construção da IP e sua relação com o trabalho (8) e construção da IP do professor (7). 


\section{Construção da Identidade Profissional e sua relação com o trabalho}

A reflexão centrada nos pressupostos e importância da aquisição da IP constituiu o foco dos estudos (e.g. WINKLER, 2011; MORAES, 2011; SILVA, 2011). O efeito da aquisição identitária no campo de trabalho e as transformações da IP decorrentes das mudanças no campo de trabalho foram também alvo de indagação (e.g. SOUZA; ROSA, 2005; FERREIRA, 2011).

Winkler (2011) e Silva (2011) elegeram a concessão da identidade como temática principal e buscaram, respetivamente, aportar entendimentos ao construto de identidade e analisar os percursos da construção da IP. Neste âmbito, para Winkler (2011), mesmo com as transformações ocorridas na sociedade e no trabalho, é possível estabilizar, através dos tempos, uma IP que se fundamenta pela fidelidade a princípios. O autor sustenta que a relevância identitária é resultado de escolhas anteriores e mudanças pessoais. Já Silva (2011) destacou as representações sociais como forma de conhecimento de si e dos outros, interferindo no sentimento de pertença. Nesse âmbito, Souza (2003) considera o trabalho um fator de forte influência na construção da identidade, pois através dele é possível assegurar a identidade, a autoestima e o reconhecimento social.

Evidenciando ainda o contexto da socialização e aquisição da IP e a sua relação com o trabalho, Tavares (2008) na área de saúde efetuou uma reflexão sobre a relação entre educação, trabalho e IP, destacando o peso dos processos de socialização na construção da IP, no processo formativo e no desempenho profissional. O mesmo autor, confirmou a influência do trabalho na construção da IP em técnicos de cardiopneumologia, numa primeira instância pelos processos de socialização, ocorridos na instituição formadora e, posteriormente, nos contextos de trabalho. Por sua vez, Carvalho (2012), também na área da saúde, afirmou que não é possível desvincular a questão da IP da formação, da história da profissão e das regras e tendências do mercado de Trabalho.

Santos (2004), recorrendo à sociedade de informação, refletiu sobre as transformações do trabalho e da IP, concluindo que ao modificar a construção e aquisição de uma IP, os processos de construção e os modos de expressão da Identidade do Homem são afetados. Acresce que a emergência da sociedade da informação induz a reconfiguração da IP (BALADELLI; FERREIRA, 2012). Nomeadamente, a interseção dos novos letramentos ${ }^{3}$ digitais com a identidade é inequívoca, porquanto ampliam o acesso dos alunos às práticas sociais de leitura e de escrita e, concomitantemente, a aquisição de uma identidade.

Por sua vez, as constantes transformações sociais nos diferentes campos de trabalho produzem forte influência na construção da IP e manutenção das relações sociais. De facto, pela socialização existente no trabalho, a necessidade de transformação e reconfiguração da identidade relacionada ao local de trabalho é uma realidade que aponta para IP dinâmicas e em constante transformação. 


\section{Construção da Identidade Profissional do professor}

O campo profissional da docência tem sido estudado de forma sustentada (ALVES et al., 2007; FERREIRA, 2011; FRANGELLA, 2003; GARCIA et al., 2005; MORAES, 2011; NUÑEZ; CARVALHO, 2005). Neste âmbito, Gomes, et al. (2013), num trabalho de revisão sistemática, constataram que nos últimos anos houve um aumento da pesquisa na temática da IP docente, colocando em evidência que o desenvolvimento profissional passa por processos de (re)construção da IP.

Ao aprofundar as investigações sobre questões da identidade e profissionalização docente, buscando entender de que forma as configurações identitárias se constituem e se transformam, Alves et al. (2007) concluíram que a IP, enquanto trajetória individual, é dinâmica e resulta das relações e interações estabelecidas nos sistemas formativos e de trabalho. Por sua vez, Moraes (2011) alertou para a importância dos processos de construção e transformação da IP docente no debate sobre a formação de professores reflexivos, advogando que a IP docente é moldada e adaptada de acordo com fatores pessoais e sociais paralelos à atuação do professor. Com efeito, como defendem Nuñez e Carvalho (2005), a pesquisa pode ser um elemento de transformação do agir docente e, consequentemente, da IP do professor. Neste sentido, acreditam que uma solução para o desenvolvimento profissional é pensar a pesquisa como elemento consistente da IP, contribuindo, assim, para a construção de novas identidades e respetiva estabilização (ALVES et al., 2007; FRANGELLA, 2003). De facto, a estabilização de uma IP docente a princípios e valores é fundamental para o desenvolvimento profissional; contudo, dado que os professores diferenciam-se entre éticas e demandas distintas, constitui um grande desafio explicar e enquadrar a IP docente em alguns tipos ideais (GARCIA et al., 2005).

A IP docente é um processo em continuum, que se processa indivualmente em contexto de interação, em resultado de múltiplos fatores, designadamente da socialização antecipatória, da formação e da atuação. É este processo de reconfiguarção da IP, pelo criar e recriar, constantemente, que influencia o desenvolvimento profissional docente.

\section{Artigos de natureza Empírica}

No que concerne aos estudos empíricos (19), a Revista Portuguesa de Educação engloba o maior número de publicações (3), seguida das revistas Educação em Revista, Revista Educação e Revista Psicologia, com 2 artigos. As restantes 10 revistas apenas englobam 1 artigo cada (Tabela 4). 
Tabela 4 - Listagem de revistas e número de estudos empíricos publicados

\begin{tabular}{l|c}
\hline Revistas & Número de artigos empíricos \\
\hline Ágora para la ef y el deporte & 1 \\
\hline Atos de pesquisa em educação & 2 \\
\hline Educação em Revista & 1 \\
\hline Educação Unisinos & 1 \\
\hline Linhas Críticas & 1 \\
\hline Psicologia, ciência e profissão & 1 \\
\hline Revista Diálogo Educacional & 2 \\
\hline Revista Educação & 1 \\
\hline Revista Mackenzie de Educação Física e Esporte & 1 \\
\hline Revista Movimento & 3 \\
\hline Revista Portuguesa de Educação & 1 \\
\hline Revista Pro-Posições & 2 \\
\hline Revista Psicologia & 1 \\
\hline Revista Teoria e Prática da Educação & 1 \\
\hline
\end{tabular}

O ano de 2011 foi o mais produtivo, totalizando 6 artigos. Entre os anos de 2003 e 2006 apenas foram publicados 2 artigos; 4 artigos a partir do ano de 2007 e 3 artigos em 2012. Em termos de local de realização, verifica-se novamente que a maioria foi publicada no Brasil (13), 2 em Portugal e 1 na Espanha.

Outra evidência centra-se na grande variabilidade da tipologia de participantes, com predominância de professores $(63,2 \%)$, professores formadores (universitários) (BASEI, 2012; VARGAS; MOREIRA, 2011) e professores do ensino básico (e.g. ABRAHÃO, 2007; PEREIRA; ENGERS, 2009; SIEMS, 2008; THIVES, 2007). Relativamente aos outros participantes, são estudantes em formação $(26,3 \%)$ (BARROS; et al., 2012; DUARTE; LIMA, 2005; LEMOS; BUENO; SILVA; GENICOLO, 2007; PARDAL; ANTÓNIO; GONÇALVES; PEDRO, 2011; SALES; CHAMON, 2011) e diretores escolares (SILVA, 2011).

Nos instrumentos de investigação, a entrevista individual (e.g. DUARTE; LIMA, 2005; THIVES, 2007; VARGAS; MOREIRA, 2011) é o instrumento mais utilizado (33\%), juntamente com as reflexões dos participantes (38\%) (narrativas e relatos) (e.g. ABRAHÃO, 2007; PEREIRA; ENGERS, 2009; RODRIGUES; FIGUEIREDO, 2011), seguindo-se os questionários (38\%) (e.g. DUARTE; LIMA, 
2005; LEMOS et al., 2007; SALES; CHAMON, 2011), observação e análise documental (BASEI, 2012) e, por fim, os grupos de discussão (BARROS et al., 2012; CUNHA; FERNANDES; MOTA; GREICE; NOGUEIRA, 2007).

Os estudos empíricos situam-se predominantemente em professores no ativo e nos processos de formação inicial, corroborando o verificado nos estudos de natureza teórica.

\section{Fatores influenciadores da (re)construção da identidade docente}

A influência dos contextos de socialização e da formação inicial na construção da IP docente, com a reflexão sobre o papel da prática no processo de reconstrução identitária dos professores são os temas dominantes. Neste processo reconstrutivo da IP, os aspetos sociais, políticos, culturais e históricos que circundam a prática docente também têm um forte contributo. Nesse âmbito, Cunha, Fernandes, Mota, Greice e Nogueira (2007) veiculam que a IP é uma construção processual e dinâmica em constante relação com o entorno educacional e social, movida pelas constantes mudanças sociais e culturais. Nesta ambiência, Lemos, Bueno, Silva e Genicolo (2007) observaram que as preferências profissionais de estudantes estão associadas aos diferentes tipos de representações sobre o papel da profissão na vida, influenciando diretamente o processo de formação da sua IP. Mais recentemente, Sales e Chamon (2011) também verificaram uma forte influência de ideários sociais nas conceções elaboradas pelos sujeitos sobre a profissão docente.

Já no que concerne à formação inicial, observa-se que a IP de base - construída antes do início da formação inicial, em resultado dos processos de socialização, designadamente no contexto da formação inicial - é essencial para a construção da IP dos futuros docentes. Neste âmbito, o contexto de formação inicial de futuros docentes deve ser uma fase de grande investimento, no que diz respeito à aquisição da IP. De facto, como ilustra o estudo de Abrahão (2007), que recorreu a narrativas de professores no ativo, existem fortes relações entre a vida formativo-profissional e a construção identitária do Ser Educador.

Barros, Gomes, Pereira e Batista (2012) e Vargas e Moreira (2011), referindo-se à construção da IP do professor de Educação Física, realizaram estudos com estudantes em formação e professores no ativo, respetivamente. Os autores concluíram que as experiências vivenciadas dos estudantes para professores enquanto alunos/atletas influenciam a sua atuação enquanto professores e que o gosto pelo esporte competitivo, na juventude do professor, parece exercer grande influência na construção da IP.

O contexto de socialização, necessário à aquisição da IP, também foi alvo de discussão por alguns autores. Neste âmbito, Thives (2007) buscou compreender, na voz dos professores, os sentidos da constituição de sua profissão e refletir sobre os saberes que envolvem a formação docente. A autora concluiu que é nas relações com os outros e seus diferentes saberes e conhecimentos, contextualizados em diferentes tempos e espaços, que a constituição docente emerge. Sendo assim, o "outro" pode ser entendido como imprescindível na constituição da IP docente, mormente os alunos ao serem parte integrante, e representativa, do processo de socialização. 
Alguns autores focaram as suas pesquisas no percurso identitário de professores (e.g. FIGUEIREDO, 2010; PEREIRA; ENGERS, 2009) e perceberam que a classe docente busca a melhoria da sua formação, remetendo para a consolidação da noção que existe uma forte ligação entre a IP docente e o trabalho exercido pelos professores. Neste âmbito, Figueiredo (2010) verificou uma correlação significativa entre a configuração da identidade pessoal e a noção social que se tem sobre a formação, o trabalho e as relações com os saberes visados e/ou construídos pelo professor. Por sua vez, Pardal, António, Gonçalves e Pedro (2011), ao analisarem as representações sociais de estudantes universitários, futuros professores, reiteram a forte relação entre a identidade do professor e o trabalho que exerce.

Por fim, ao analisar o percurso identitário de professoras com o objetivo de revelar fragmentos dos processos da constituição da identidade docente, Gesser (2011) constatou que há professoras que utilizam a profissão docente como estratégia para quebrar regras implícitas na realidade social em que estão inseridas, ficando visível a inferência externa na IP docente, muitas vezes, decorrente do contexto de socialização.

\section{A Identidade Profissional docente e o contexto [lugar e espaço] de intervenção}

A identidade adquirida molda-se de acordo com expectativas mas também de acordo com o contexto de inserção. Neste âmbito, Bonomo, Trindade, Souza e Coutinho (2008) concluíram que a construção e a transformação da identidade ocorrem através de um processo contínuo de identificação, exemplificando que as pessoas, quotidiamente, se associam a diferentes grupos sociais, como por exemplo rural, cigano, homens, mulheres, assumindo, portanto, diferentes identidades. A classe docente é mais um exemplo de grupo que necessita de uma forte ligação com a profissão, uma identidade que esteja intrincada nos ideais dos profissionais e nos valores da profissão.

Ainda neste grupo profissinal, considera-se que existem divisões e IP docentes específicas em cada setor. Como nos mostram Marta e Lopes (2012), na análise que efetuaram aos efeitos das experiências de trabalho no sector público nas identidades de educadores de infância, as experiências no sector público traduzem-se na emergência de uma identidade típica desse sector, que se orienta por princípios que usualmente definem a educação pública.

Rodrigues e Figueiredo (2011), a partir de relatos de experiências relacionais vivenciadas por uma professora em contetxo de formação inicial, procuraram compreender como esta construiu a sua IP nos contextos relacionais da sua atuação. Este contetxo formativo mostrou ser um instrumento teórico e metodológico de reflexão sobre o dia-a-dia profissional e movilizador de conhecimentos pessoais e profissionais da docência. Basei (2012), ao procurar entender como os processos de construção da IP docente podem influenciar as ações pedagógicas desenvolvidas verificou que é na formação inicial que se começa a construir a IP de base.

Outro elemento analisado nos estudos é a relação das políticas públicas e do sistema educacional, que exercem influência direta no processo de construção da IP 
docente (SIEMS, 2008; SILVA, 2011). Recorrendo à análise documental e à relação com o discurso direto de diretores escolares, Silva (2011) aponta que a construção da identidade é um processo que passa pelas diferentes regulações estabelecidas tanto socialmente, como pela política educacional, bem como pela prática cotidiana escolar. Já Siems (2008), recorrendo a histórias de vida acadêmica e profissional de docentes que atuam na educação de pessoas com deficiência, analisou o modo como essas docentes construiram a sua IP. A a autora destaca a crise que envolve a profissionalidade docente e o modo como atualmente o sistema educacional se encontra estruturado.

Noutra vertente, Duarte e Lima (2005) procuraram reconhecer os conteúdos identitários subjacentes à identidade associada ao lugar, destacando: a existência de constância nas características e dimensões, com base nas quais as pessoas avaliam e edificam a sua identidade associada ao lugar; uma identificação forte com os lugares projeta uma visão mais positiva dos mesmos, mais funcional, mais estética, mais rica em património histórico e cultural. $\mathrm{Na}$ sua essência, a identidade associada ao lugar constitui uma subestrutura da identidade pessoal, remetendo para a noção de que a identidade não é um dado estável, ela molda-se e reconfigura-se à medida em que o indivíduo se expõe a processos de socialização.

\section{Conclusões}

Da revisão infere-se que não obstante as pesquisas acerca da identidade e IP em língua portuguesa estarem a aumentar na última década (2003 - 2013), com maior incidência a partir de 2007, ainda é baixo o número de publicações e quase confinada à área da docência. As publicações ocorreram maioritariamente no Brasil e repartiramse por estudos de natureza teórica (16) e empíricos (19), publicados em 29 revistas distintas. As metodologias qualitativas predominam, sendo que a entrevista individual, juntamente com relatos e narrativas são os instrumentos mais utilizados.

O estudo colocou em evidência que a IP é um construto de natureza dinâmica, em constante transformação em resultado das práticas diárias, começando antes da formação inicial e prolongando-se ao longo do exercício profissional. De facto, ficou claro que a IP não se constrói no espaço individual, mas é construída através de processos de negociação por recurso a diálogos com outros significativos, em que as representações acerca de si e dos outros são elementos importantes. Infere-se ainda que o que o exercício profissional competente se relaciona diretamente com o processo e (re)construção e (re)configuração identitária, porquanto o profissional necessita de dar resposta adequada aos novos desafios colocados pela profissão, resultantes de regulações estabelecidas tanto socialmente, como politicamente, marcadas pela agenda das novas tecnologias. A IP deixou de ser vista como um atributo do Self para passar a ser entendida como um processo de reconstrução no social, aportando multidimensionalidade ao construto.

Neste entendimento, o processo de reconstrução da IP aporta implicações ao modo como a formação continuada deve ser concebida, isto é, incorporando processos de interação social, de partilha com os pares, em que o conhecimento experiencial ganhe relevo em detrimento de uma formação centrada no conhecimento conceitual. 
Por último, no que concerne à pesquisa da IP, há necessidade de alargar o campo a outros contextos profissionais que não o de professor, investindo em abordagens qualitativo-interpretativas, com lentes analíticas voltadas para o exame das mudanças da IP, em relação a fatores contextuais, a discursos e cognições dos profissionais. Este é o caminho que permitirá conhecer melhor os contextos e as necessidades inerentes ao exercício da profissão e, consequentemente, a (re)construção da IP.

\section{Agradecimentos}

Estudo elaborado no âmbito de um projeto científico financiado pelo FEDER (Fundo Social Europeu) através do programa Operacional Factores Competividade (COMPETE) e pela Fundação para a Ciência e Tecnologia (Portugal) no âmbito do projeto PTDC/DES/120681/2010-FCOMP-01-0124-FEDER-0200047.

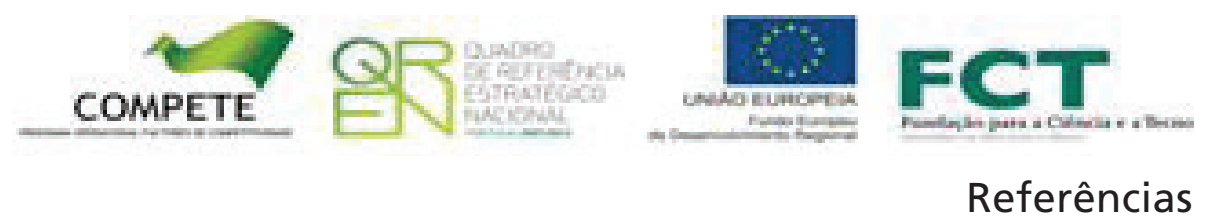

ABRAHÃO, M. Profissionalização docente e identidade - A invenção de si. Educação, Porto Alegre, v. XXX, n. especial, p. 163-185, outubro. 2007.

AKKERMAN, S.; MEIJER, P. A dialogical approach to conceptualizing teacheridentity. Teaching and Teacher Education, v. 27, n. 2, p. 308-319, fev. 2011.

ALVES, C. et al. Identidade profissional de professores: um referencial para pesquisa. Educação e Linguagem, São Paulo, v. 10, n. 15, p. 269-283, jan./jul. 2007.

AUGÉ, M. Não-lugares: introdução a uma Antropologia da sobremodernidade. Lisboa: Bertrand, 1994.

BALADELI, A. P.; FERREIRA, A. Educação e novos letramentos digitais: colaboração e construção de identidades. Quaestio, São Paulo, v. 14, n. 1, p. 9-18, maio. 2012.

BARROS, I. et al. Experiências prévias na (re)configuração da identidade profissional: um estudo com estudantes estagiários de Educação Fisíca. Ágora para la EF y el Deporte, Valladolid, v. 14, n. 3, p. 303-319, setembro/dezembro. 2012.

BASEI, A. O desenvolvimento profissional e a construção da identidade do professor de Educação Física do Ensino Superior. Revista Mackenzie de Educação Física e Esporte, São Paulo, v. 11, n. 1, p. 44-60, jan./jul. 2012.

BEAUCHAMP, C.; THOMAS, L. Preparing prospective teachers for a context of change: reconsidering the role of teacher education in the development of identity. Cambridge Journal of Education, Cambridge, v. 39, n. 2, p. 175-189, maio. 2009.

BEIJAARD, D.; MEIJER, P.; VERLOOP, N. Reconsidering research on teachers' professional identity. Teaching and Teacher Education, v. 20, p. 107-128, fev. 2004.

BONOMO, M. et al. Representações sociais e identidade em grupos de mulheres ciganas e rurais. Psicologia, Lisboa, v. XXII, n. 1, p. 153-181, jan./jul. 2008.

CARDOSO, I., BATISTA, P., GRAÇA, A. Aprender a ser professor em comunidade de prática: um estudo com estudantes estagiários de Educação Física. In: BATISTA, P.; GRAÇA, A., QUEIRÓS, P. (Eds.). O estágio profissional na (re)construção da identidade profissional em Educação Física. Porto: Editora FADEUP, 2014. p.181-207. ISBN 978-972-8687-65-6. 
CARVALHO, C. R. A Identidade Profissional dos Terapeutas Ocupacionais: considerações a partir do conceito de estigma de Erving Goffman. Saúde Sociedade, São Paulo, v. 21, n. 2, p. 364-371, abr./jun. 2012.

CUNHA, R. et al. Professor/a: os elementos de uma identidade em construção. Pro-Posições, Campinas, v. 18, n. 1, p. 153-167, jan./abr. 2007.

DESCHAMPS, J. C.; MOLINER, P. A identidade em psicologia social: dos processos identitários às representações sociais. Tradução de Lúcia M. Endlich Orth. Petrópolis: Vozes, 2009.

DENYER, D.; TRANFIELD, D. Using qualitative research synthesis to build an actionable knowledge base. Management Decision, Surrey, v. 44, n. 2, p. 213-227, jan. 2006.

DUARTE, A. P.; LIMA, M. L. Análise dos conteúdos da identidade associada ao lugar. Psicologia, Lisboa, v. 19, p. 193-226. 2005.

DUBAR, C. La Socialisation. 2a edição. Paris: Armand Colin, 1995.

. A Socialização: construção das identidades sociais e profissionais. Porto: Porto, 1997.

FACCI, M. G. Valorização ou esvaziamento do trabalho do professor: um estudo críticocomparativo da teoria do professor reflexivo, do construtivismo e da psicologia vigotskiana. Campinas: Autores associados. 2004.

FERREIRA, M. Construção de identidades docentes: Entre a vocação, as necessidades objetivas e os processos sociais. Educação, Porto Alegre, v. 34, n. 1, p. 106-113, jan./abr. 2011.

FIGUEIREDO, Z. Experiências profissionais, identidades e formação docente em educação física. Revista Portuguesa de Educação, Braga, v. 23, n. 2, p. 153-171, jul./dez. 2010.

FISHER, G. Psicologia social do ambiente. Lisboa: Instituto Piaget, 1994.

FRANGELLA, R. Formação docente e a emergência de uma nova identidade profissional - A revista Escola Secundária da Cades (1957-1963). Teias, Rio de Janeiro,v. 4, n. 7-8, p.1-8,jan./dez. 2003.

GARCIA, M.; HYPOLITO, Á.; VIEIRA, J. As identidades docentes como fabricação da docência. Educação e Pesquisa, São Paulo, v. 31, n. 1, p. 45-56, janeiro/abril. 2005.

GEE, J. P. Identity as an analytic lens for research in education. Review of Research In Education, Florida, v. 25, 99-125. 2001.

GESSER, V.; SANTOS, Z. Identidade docente: Estudo das concepções pedagógicas documentadas e o distanciamento da prática vigente. Rev. Teoria e Prática da Educação, Maringá, v. 14, n. 2, p. 21-31, maio/agosto. 2011.

GIDDENS, A. Modernidade e identidade pessoal. Oeiras: Celta, 1994.

Modernidade e identidade pessoal. 2. ed. Oeiras: Celta, 1997.

GOMES, P.; et al. A identidade profissional do professor: Um estudo de revisão sistemática. Rev Bras Educ Fís Esporte, São Paulo, v. 27, n. 2, p. 247-267, abril/junho. 2013.

GUIMARÃES, V. S. Formação de professores: saberes, identidade e profissão. Campinas: Papirus, 2004.

HYPOLITO, A. M. Processo de trabalho na escola: uma análise a partir das relações de classe e de gênero. Belo Horizonte: Universidade Federal de Minas Gerais, 1994. Dissertação (Mestrado) - Universidade Federal de Minas Gerais, Belo Horizonte, 1994.

. Relações de gênero e de classe social na análise do trabalho docente. Cadernos de Educação, Pelotas, n. 4, p. 5-18, março. 1995.

Trabalho docente, classe social e relações de gênero. Campinas: Papirus, 1997. 
LAWN, M. Os professores e a fabricação de identidades. In: NÓVOA, A (Ed.). A difusão mundial da escola. Lisboa: Educa, 2000. p. 69-84.

LEMOS, C. et al. Referenciais de carreira e identidade profissional em estudantes universitários. Psicologia, Ciência e Profissão, Brasília, v. 27, n. 2, p. 208-223, junho. 2007.

LIMA, S.; COELHO, A. Sociedade pós-salarial: Não-locais de trabalho, riscos psicológicos e algumas questões de saúde ocupacional. Revista da UFP, Porto, n. 4, 203 212, dezembro. 1999.

LOPES, A. Libertar o desejo, resgatar a inovação: a construção de identidades profissionais em docentes do $1^{\circ}$ CEB. Porto: Faculdade de Psicologia e de Ciências da Educação da Universidade do Porto, 1999. Tese (Doutoramento) - Faculdade de Psicologia e de Ciências da Educação da Universidade do Porto, 1999.

LOPES, A. et al. Estudo exploratório sobre sobre currículo de formação de formação inicial e identidade profissional de docentes do $1^{\circ} \mathrm{CEB}$ : Indícios sobre o papel do envolvimento dos estudantes na gestão do seu currículo de formação. Revista Portuguesa de Educação, Braga, v. 17, n. 1, p. 63-95, janeiro/julho. 2004.

MARTA, M.; LOPES, A. Setor público e identidades profissionais em educação de infância: Transformações e permanências na última década. Revista Portuguesa de Educação, Braga, v. 25, n. 1, p. 29-52, janeiro/julho. 2012.

MESQUITA, I. Towards a new paradigm in coach education. In: BENTO, J.; TANI, G.; PRISTA, A. (Eds.). Sport and Physical Education in Portuguese. Porto: CIFID, Faculty of Sport, University of Porto, 2010. p. 84-99.

MESQUITA, I. et al. Construção da identidade profissional em educação física: da formação à intervenção. In: NÁSCIMENTO, J.; FARIAS, G. (Eds.). Nova abordagem na formação de treinadores: o que mudou e porquê? Florianópolis: Ed. UDESC, 2012, p. 41-60.

MORAES, J. Para uma crítica dos discursos da identidade reflexiva. Educação em Perspectiva, Viçosa, v. 2, n. 2, p. 211-222, julho/dezembro. 2011.

NÓVOA, A. Vidas de Professores. Porto: Porto Editora, 2000.

NUÑEZ, I.; RAMALHO, B. A pesquisa como recurso da formação e da construção de uma nova identidade docente: Notas para uma discussão inicial. EccoS, São Paulo, v. 7, n. 1, p. 87-111, junho. 2005.

OLIVEIRA, R. Identidade étnica, identificação e manipulação. Sociedade e Cultura, Goiás, v. 6, n. 2, p. 117-131, julho/dezembro. 2003.

OWENS, T.; ROBINSON, D.; SMITH, L. Three faces of identity. Annual Review of Sociology, Palo Alto, v. 36, p. 477-499, abril. 2010.

PARDAL, L. et al. Quando for grande vou ser professor: A identidade docente representada por futuros professores. Rev. Diálogo Educ., Paraná, v. 11, n. 33, p. 417-433, maio/agosto. 2011

PEREIRA, G.; ENGERS, M. E. Identidade profissional docente: Uma construção histórico-sociocultural. Educação, Porto Alegre, v. 32, n. 3, p. 291-310, setembro/ dezembro. 2009.

PETTICREW, M.; ROBERTS, H. Systematic Reviews in the Social Sciences: A Practical Guide. Cornwall: Blackwell Publishing, 2006.

PIMENTA, S. G. Formação de Professores: identidade e saberes da docência. In: 
PIMENTA, S. G. (Ed.). Saberes pedagógicos e atividade docente. 4a edição. São Paulo: Cortez, 2005.

RODRIGUES, R.; FIGUEIREDO, Z. Construção identitária da professora de Educação Física em uma instituição de educação infantil. Movimento, Porto alegre, v. 17, n. 4, p. 65-81, outubro/dezembro. 2011.

SALES, A; CHAMON, E. Escolha da carreira e processo de construção da identidade profissional docente. Educação em Revista, Belo Horizonte, v. 27, n. 3, p. 183-210, dezembro. 2011.

SANTOS, N. Emergência da cultura do efémero no contexto sócio-laboral e identidade profissional: Dos não-lugares aos não-locais de trabalho. Antropológicas, Porto, n. 8, 83-91. 2004.

SAVIN-BADEN, M.; MAJOR, C. Qualitative Research Synthesis: The Scholarhip of Integration in Practice. In: ___ New Approaches to Qualitative Research: Wisdom and Uncertainty. Oxon: Routledge, 2010. p. 108-118.

SIEMS, M. E. Educação especial em tempos de educação inclusiva: A identidade docente em questão. Linhas Críticas, Brasília, v. 14, n. 27, p. 209-226, julho/dezembro. 2008.

SILVA, J. construção da identidade de diretores: Discurso oficial e prática. Educação em Revista, Belo Horizonte, v. 27, n. 3, p. 211-230, dezembro. 2011.

SILVA, G. identidade em psicologia social: Dos processos identitários às representações sociais. Rev. Diálogo Educ., Coritiba, v. 11, n. 33, p. 603-607, maio/agosto. 2011.

SOUZA, J. A construção social da subcidadania: para uma sociologia política da modernidade periférica. Rio de Janeiro: Editora UFMG, 2003.

SOUZA, V.; ROSA, A. Políticas públicas e a construção da identidade nas relações de trabalho. Civitas - Revista de Ciências Sociais, Porto Alegre, v. 5, n. 1, p. 197-212, janeiro/junho. 2005.

STETS, J.; BURKE, P. Identity theory and social identity theory. Social Psychology Quarterly, Washington, v. 63, n. 3, p. 224-237, Setembro. 2000.

TAVARES, D. (2008). Identidade, socialização e processo de profissionalização - Contributos de um estudo sobre os técnicos de cardiopneumologia. Sísifo / Revista de Ciências da Educação, Lisboa, n. 6, p. 35-44, maio/agosto. 2008.

THIVES, P. Na voz do professor, a constituição de sua identidade. Atos de Pesquisa em Educação, Santa Catarina, v. 2, n. 2, p. 274-282, maio/agosto. 2007.

VARGAS, C.; MOREIRA, A. Identidades em desalinho: Um estudo de campo na formação em educação física. Educação Unisinos, São Leopoldo, v. 15, n. 3, 214-223, setembro/dezembro. 2011.

NUNNER-WINKLER, G. Formação da identidade em tempos de mudanças velozes e multiplicidade normativa. Educação, Porto Alegre, v. 34, n. 1, p. 56-64, janeiro/abril. 2011.

Notas

\footnotetext{
${ }^{1}$ Para Dubar, a identidade para o próprio não se separa da identidade para o outro. Ao nível pessoal, ou para si, reporta-se ao modo como o individuo se vê, em função da sua biografia e das projeções e expectativas que tem relativamente ao seu futuro. A identidade ao nível coletivo, ou para o outro, tem a ver com o modo como a pessoa é percebida, valorizada por aqueles com quem interage ao longo de sua vida pessoal e profissional.
} 
${ }^{2}$ Qualis é o conjunto de procedimentos utilizados pela Coordenação de Aperfeiçoamento de Pessoal de Nível Superior (CAPES) para estratificação da qualidade da produção intelectual dos programas de pósgraduação.

${ }^{3}$ Termo utilizado pelo autor que significa o resultado da ação de ensinar a ler e escrever.

* Mestre pela Faculdade de Desporto da Universidade do Porto, Porto, Portugal.

** Professora doutora da Faculdade de Desporto da Universidade do Porto, Porto, Portugal.

*** Professora doutora da Faculdade de Desporto da Universidade do Porto, Porto, Portugal.

\section{Correspondência}

Isabel Mesquita - Faculdade de Desporto da Universidade do Porto, Gabinete de Voleibol.

Rua Dr. Plácido Costa, 91, 4200.450, Paranhos, Porto - Portugal.

E-mail: lucianovozniak@hotmail.com - imesquita@fade.up.pt - paulabatista@fade.up.pt

Recebido em 18 de outubro de 2015

Aprovado em 21 de dezembro de 2015 